\title{
Editorial
}

\section{Are current competitive pressures causing financial institutions to get 'stuck in the middle'?}

Looking back over the last 30 years or so on the history of development of the financial services sectors of most developed nations, one might think the financial institutions back then had it easy: competitive pressures and strategic and marketing decisions seemed to be fewer than those facing them today.

Just over 30 years ago, financial institutions had fewer competitors: banks competed with banks and insurance companies competed with insurance companies. Today banks, building societies and insurance companies all compete with one another in addition to new entrants on the financial services scene such as supermarkets, utilities companies and retailers as well as third party organisations. Moreover, competition is no longer restricted to the regional or national level but is now global.

For most types of financial institution, there was only one channel to operate; for banks and building societies it was primarily the branches and for insurance companies it was primarily the direct sales force. The advent of technology has introduced a wider array of channels, not only giving the consumer multiple means of access but also making contact more remote. Now the multi-channel strategy is more the norm.

The legacy systems that many financial institutions are now working hard to improve were state-of-the-art then and did everything that the business required of them. As financial institutions have evolved, however, from a narrow product-market-channel focus to a multiple product-market-channel proposition, the legacy systems have not kept pace and are now outdated and restrictive.

Today's picture is quite different from the competitive scene of 30 years ago. Consequently, financial institutions are being placed under increasing pressure, from fierce competition and limited resources. To survive, many financial institutions are taking actions to cut costs, improve operations and streamline decision making while also improving quality and service. There is a danger that some financial institutions, while attempting to be all things to all stakeholders, are ending up getting 'stuck in the middle': a situation defined by Michael Porter ${ }^{1}$ which typifies an unclear strategy and no real competitive advantage.

According to Porter, a key determinant of a firm's profitability is the position it occupies within its industry. A firm positions itself by leveraging its strengths. Strengths can fall into one of two primary domains: cost advantage or differentiation. By applying these strengths in either a broad (industry-wide) or narrow (segment-specific) scope, three generic strategies result: cost leadership, differentiation or focus. A cost leadership strategy requires the firm to be a low-cost producer in order either to increase profit 
margins or to lower prices to increase market share. Differentiation calls for the development of products or services that offer unique attributes or are valued by customers and perceived to be different. The added value usually allows firms to charge premium prices. The focus strategy requires firms to concentrate efforts on a specific segment and achieve either cost advantage or differentiation.

The generic strategies are not necessarily compatible with one another. Attempting to achieve an advantage in all areas can result in no advantage being achieved at all. The message becomes confused to the marketplace and consumers become distrustful that a firm can offer high quality at the lowest possible price. This is when firms become 'stuck in the middle', attempting to apply multiple strategies. Multiple strategies can work, however, by applying different strategies at different business unit levels. So, a distinction needs to be made between the corporate level and the business unit level in terms of what the overall strategy should be and the message that is conveyed to the market. It is clear that certain areas of business, such as general insurance and credit cards, are very price sensitive and companies are attempting to leverage their low-cost advantage in these areas. In other areas service quality is more important, and there are many examples of financial institutions developing CRM programmes to improve quality and service to customers and win the customer's loyalty.

At a time of such intense competitive pressure, the need for up-to-date research and insight to guide firms becomes more important. Now in its ninth volume, the Journal of Financial Services Marketing will be bringing research, commentary and real case examples to assist financial institutions in their fight for competitive advantage. Papers forthcoming in this volume represent extensive coverage of both practitioner and academic concerns in the marketing of financial services, providing key insight into how to gain a competitive advantage and avoid becoming 'stuck in the middle'.

In this particular issue, I am delighted to present a comprehensive coverage of the key concerns of financial institutions from customer relationships and use of customer data to key elements of the marketing mix, such as pricing and distribution, to legal issues and their impact on marketing. Not only do the papers provide an excellent coverage of the marketing issues, but also take account of different country contexts, spanning Europe (the UK and Greece) and the USA, and take account of different industry contexts as well, from traditional banks and insurance companies to new supermarket banks.

Two papers in this issue address different aspects of CRM: customer data and cross-selling. For financial institutions, the impact of legacy systems on customer data management has been profound. Paradoxically, financial institutions are in an enviable position vis-à-vis the amount and quality of data they capture on their customers, yet the way in which data have been stored and managed in the past has made it difficult to unlock their full marketing potential. The paper by Chris Todman and Mick James outlines in detail the business and technical issues involved in transforming Standard Life from a product-oriented services organisation to a customer-centric organisation. Rarely do companies share such details of how they have solved a problem to achieve competitive advantage. The paper not only chronicles the experience of Standard Life through this transformation of customer data management, but also illustrates the value that can be gained from more effective use of the data for marketing purposes. This ranges from activities as simple as making relevant mailshots, to more advanced data applications and analysis designed to track 
behaviour and predict future needs. So much of what is achieved by marketing departments in financial institutions relies on good quality customer data, without which it is not possible to conduct reliable analyses of customer behaviour.

The paper by Konstantinos Lymberopoulos et al. identifies the opportunities for banks to cross-sell insurance products through their branch networks. While the context is Greek banks, the findings of the research have broader appeal, recognising the trend towards bancassurance and the need for banks to increase their ability to cross-sell across product ranges. The study consisted of a questionnaire survey of 720 bank customers. The research finds that there is a relatively low awareness among banking consumers regarding the availability of insurance products offered by banks, compared with their willingness to buy such products from banks. This suggests that banks are missing an opportunity to sell more insurance through their branches and would benefit from improved communication in order to increase general awareness of what is on offer to customers.

On the subject of distribution and delivery, two papers focus on two quite separate and important issues. The paper by Helen White and Fotini Nteli questions why there are not more internet bank customers. Despite the increase in the number of internet users generally, the use of the internet for banking purposes has not increased at the same rate, and the UK is also lagging behind some other countries when it comes to internet banking. Security issues are perceived to be a main factor inhibiting greater consumer involvement, but at the same time consumers are also demanding greater levels of service quality. In an attempt to understand the issues surrounding barriers to adoption and increased use, the research presents the findings of interviews with 56 internet banking customers. Five key service quality attributes were investigated: credibility, product variety, security, responsiveness, and ease of use. Consumers rated internet banks highly on all attributes with the exception of product variety, suggesting that the internet channel perhaps does not meet all customer needs and, as some banks have already recognised, indicates the importance of a multi-channel strategy. The research also identified two very different segments of internet bank users: one group for whom credibility and security are key issues, and one group favouring responsiveness and ease of use. Understanding the segment differences may be crucial in understanding low internet use and increasing involvement.

From attempting to understand why an established technology has not been adopted fully, Ben Hourahine and Melanie Howard's paper seeks to identify and quantify the likely shape of consumer demand for a relatively new technology: mobile voice and data services. With increasing mobility both at home and at work, comes a desire and a need to be able to access and conduct financial transactions while on the move. The increase in mobile technology such as mobile phones, which has now reached over 80 per cent penetration in the UK, makes this a real opportunity for financial institutions. While the need exists among consumers, however, there is relatively little use made of mobile devices for financial services at the moment. Research by the Future Foundation, using time diaries with 278 'hyper-mobile' consumers, identifies gaps in current financial services provision which could easily transfer to the mobile environment. While the biggest demand is for account servicing functions (such as checking account balances and bill payments), the research identifies the potential to develop a new offering labelled 'guardian services'. The 
research also identifies that while certain types of people intrinsically prefer either data or voice services, in the main it depends on the situation or context of the consumer.

On the subject of pricing, the paper by Samuel Krikler and colleagues presents a methodology for the optimisation of insurance price and revenue. This essentially means determining what products and services to offer to which customer segments, through which channels and at what prices in order to maximise profit. The study focuses on car insurance in the USA, although the findings are of value to other general insurance markets where price competition is becoming increasingly intense. The paper describes an actual price optimisation process using data collected from a sample of over 10,000 customers. The subsequent price optimisation process generated a real impact on profitability.

With regard to type of institution, the paper by Charles E. Pettijohn et al., explores some of the differences between traditional and supermarket banks in the US context in terms of the impact on employees' attitudes regarding product offerings, job satisfaction and turnover. The advent of supermarket banks has had a significant impact on the nature of the branch environment in the USA.

Traditionally, bank employees tended to be housed in a central location, the culture was relatively stable and known to customers and employees. In contrast, many employees of supermarket banks are no longer under the direct supervision of bank management, the culture may be vague and with this the potential for inconsistency in service quality. Research evaluated the environmental changes in terms of their impact on the employees' perceptions of customer attitudes and found that supermarket bank employees were less attuned to the customer and supermarket banks would be well advised to undertake some training of branch employees to ensure that marketing opportunities are not lost over the counter.

The papers discussed so far relate primarily to factors within the control of the financial institution. There are also a number of external factors that occur in the broader business environment, however, that have an impact on the way institutions operate. One of the key external influences on financial institutions is the regulatory or legal environment. In this context the paper by Galina Andreeva et al. discusses the impact of anti-discrimination laws on credit scoring. The issue arises from greater political harmonisation with the European Union which, while beneficial in many ways, allows the potential for malpractice. Previously, credit granting rules were determined at the national level, yet EU directives seek to harmonise national rules and provide guidance on the variables or information that may be used in making credit decisions. The major concern relates to the issue of discrimination. The law aims to promote equal treatment, however, this can be interpreted in a number of ways and the legal interpretation does not necessarily coincide with the economic standpoint. There is a danger that prohibiting the use of certain variables (information) in credit decisions may not only adversely affect the ability of the credit grantor to distinguish between good and bad risks, but may also be disadvantageous to the groups that the legislation is designed to protect.

Finally, the legal update by Brigid Breslin of McDermott, Will and Emery and Daniel Rabinowitz brings us up to date on the Prospectus Directive which is due to come into force on 1st July, 2005. The Directive will harmonise the requirements for the content, approval and publication of prospectuses in relation to offers of securities to the public and 
applications to admit securities to trading on a regulated market in the EU. This will have implications for the communication and marketing material related to securities. The paper provides the mechanics of the new regime and how it will affect firms.

I hope you find this issue and forthcoming issues of the Journal stimulating and valuable.

\section{REFERENCE}

1 Porter, M. (1985) 'Competitive Advantage: Creating and Sustaining Superior Performance', The Free Press, New York.

Tina Harrison Managing Editor 